\title{
Endocrine sequelae of immune checkpoint inhibitors
}

\author{
Georgia Ntali, ${ }^{1}$ Eva Kassi, ${ }^{2,3}$ Maria Alevizaki ${ }^{3,4}$
}

${ }^{1}$ Department of Endocrinology, Diabetes and Metabolism, Evangelismos Hospital, Athens, Greece; ${ }^{2}$ Department of Biological Chemistry, National and Kapodistrian University of Athens, School of Medicine, Athens, Greece; ${ }^{3}$ Endocrine Unit, Department of Medical Therapeutics, Alexandra Hospital, Athens University School of Medicine, Athens, Greece; ${ }^{4}$ Endocrine Unit, Athens University, Evgenideion Hospital, Athens, Greece

\begin{abstract}
Cancer immunotherapy has introduced a novel class of drugs known as immune checkpoint inhibitors (ICIs). They enhance antitumour immunity by blocking negative regulators (checkpoints) of $T$ cell function that exist on both immune and tumour cells. ICIs targeting CTLA-4 and PD-1/PDL-1 have dramatically changed the outcome of patients with several advancedstage malignancies but they may lead to a variety of inflammatory toxicities and autoimmune consequences. The main endocrine immune-related adverse events (IRAEs) include hypophysitis, primary thyroid dysfunction, adrenalitis and type 1 diabetes mellitus. In general, the management of endocrine IRAEs requires assessment of their severity, in moderate or severe cases interruption of the checkpoint inhibitor and use of corticosteroid or alternative immunosuppression and appropriate hormone replacement or treatment when necessary.
\end{abstract}

Key words: Anti-CTLA4, Anti-PD1, Anti-PDL1, Autoimmune consequences, Immune checkpoint inhibitors

\section{INTRODUCTION}

Cancer immunotherapy has introduced a novel class of drugs known as immune checkpoint inhibitors (ICIs). They enhance antitumour immunity by blocking negative regulators (checkpoints) of $\mathrm{T}$ cell function that exist on both immune and tumour cells. The first agent was approved in 2011 and since then a few of them have been evaluated in clinical trials for the management of advanced neoplasias, such as metastatic melanoma, non-small cell lung cancer,

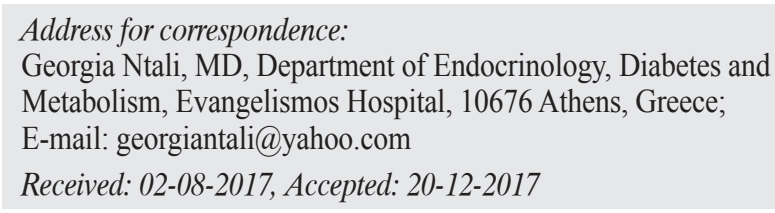

advanced renal cell carcinoma, head and neck cancer and lymphoma (Table 1). ${ }^{1-5}$ However, because of their mechanism of action these agents can lead to a variety of inflammatory toxicities and autoimmune consequences that can affect the gastrointestinal tract, skin, liver and endocrine system and are hence described as immune-related adverse events (IRAEs). The endocrine immune-related adverse events include hypophysitis, primary thyroid dysfunction, adrenalitis and type 1 diabetes mellitus which present with variable degrees of severity ${ }^{6-11,38}$ (Table 2) and incidence rates $^{47}$ (Table 3 ).

\section{PATHOGENIC MECHANISMS}

Tumour antigens are presented by dendritic cells 
Table 1. FDA approved immune check point inhibitors

\begin{tabular}{|c|c|}
\hline $\begin{array}{l}\text { Product } \\
\text { Generic name (Brand name) }\end{array}$ & Indication for the treatment of patients with cancer \\
\hline \multicolumn{2}{|l|}{ Anti-CTLA4 } \\
\hline Ipilimumab (Yervoy) & $\begin{array}{l}\text { cutaneous melanoma } \\
\text { unresectable or metastatic melanoma }\end{array}$ \\
\hline Tremelimumab & malignant mesothelioma \\
\hline \multicolumn{2}{|l|}{ Anti-PDL1 } \\
\hline Atezolizumab (Tecentriq) & $\begin{array}{l}\text { locally advanced or metastatic urothelial carcinoma } \\
\text { metastatic squamous cell carcinoma of the head and neck }\end{array}$ \\
\hline Avelumab (Bavencio) & $\begin{array}{l}\text { locally advanced or metastatic urothelial carcinoma } \\
\text { metastatic Merkel cell carcinoma (MCC) }\end{array}$ \\
\hline Durvalumab (Imfinzi) & $\begin{array}{l}\text { locally advanced or metastatic urothelial carcinoma } \\
\text { metastatic Merkel cell carcinoma (MCC) }\end{array}$ \\
\hline \multicolumn{2}{|l|}{ Anti-PD1 } \\
\hline Nivolumab (Opdivo) & $\begin{array}{l}\text { locally advanced or metastatic urothelial carcinoma } \\
\text { recurrent or metastatic squamous cell carcinoma of the head and neck } \\
\text { renal cell carcinoma } \\
\text { unresected or metastatic melanoma } \\
\text { non-small cell lung cancer } \\
\text { classical Hodgkin lymphoma that has relapsed or progressed after autologous hematopoietic stem } \\
\text { cell transplantation }\end{array}$ \\
\hline Pembrolizumab (Keytruda) & $\begin{array}{l}\text { adult and pediatric patients with unresectable or metastatic, microsatellite instability-high (MSI-H) } \\
\text { or mismatch repair deficient (dMMR) solid tumors } \\
\text { locally advanced or metastatic urothelial carcinoma } \\
\text { refractory classical Hodgkin lymphoma } \\
\text { recurrent or metastatic head and neck squamous cell carcinoma } \\
\text { unresectable or metastatic melanoma. } \\
\text { metastatic non-small cell lung cancer }\end{array}$ \\
\hline Nivolumab + ipilimumab & BRAF V600 wild-type, unresectable or metastatic melanoma \\
\hline
\end{tabular}

to cytotoxic T lymphocytes (CTLs). The activation of $\mathrm{T}$ cells is regulated by stimulatory and inhibitory signals that maintain the balance between appropriate recognition and destruction of tumour cells and inappropriate immune overstimulation, which damages normal healthy tissue. This is referred to as the cancer-immunity cycle. ${ }^{12} \mathrm{~T}$ cell-mediated inhibitory signalling pathways permit tolerance to tumour antigens. Although there are many $\mathrm{T}$ cell checkpoints, antibodies against cytotoxic T-lymphocyte antigen 4 (CTLA4), programmed cell death 1 (PD1) and programmed cell death 1 ligand 1 (PDL1) have been most extensively evaluated in the clinical setting. The available data refer to ipilimumab and tremelimumab, both CTLA4-abs, nivolumab, pembrolizumab and pidilizumab, all anti-PD1 abs and atezolizumab an anti-PDL1 agent.
Anti-CTLA4

CD28 on the T cell surface binds to the B7 co-stimulatory ligand on antigen-presenting cells to prime and activate the $\mathrm{T}$ cell so as to destroy the cancer cells. CTLA4, which is a CD28 homolog, binds with higher affinity to B7 and can compete with CD28 to inhibit $\mathrm{T}$ cell activity. This process prevents the $\mathrm{T}$ cell from killing the cancer cells. Antibodies to CTLA4 prevent B7 binding and enable upregulation of T cell activity, activation of mitogen-activated protein kinase which results in the formation of activator protein 1 (AP1) complex and induction of IL-2 cytokines which mediate $\mathrm{T}$ cell growth. ${ }^{13-15}$

\section{Anti-PD1 and anti-PDL1}

The PD1 (programmed cell death - 1) receptor (also known as CD279) is expressed on the surface of 
Table 2. Classification of endocrine adverse events and diagnostic criteria

\begin{tabular}{|c|c|c|c|c|c|}
\hline & Grade 1 & Grade 2 & Grade 3 & Grade 4 & Grade 5 \\
\hline Hypophysitis & $\begin{array}{l}\text { Asymptomatic or mild } \\
\text { symptoms (mild fatigue, } \\
\text { anorexia, no headache); } \\
\text { clinical or diagnostic } \\
\text { observations only; } \\
\text { intervention not indicated }\end{array}$ & $\begin{array}{l}\text { Moderate (i.e. fatigue, } \\
\text { mood alteration, headache } \\
\text { but without visual } \\
\text { disturbances) minimal, } \\
\text { local or noninvasive } \\
\text { intervention indicated; } \\
\text { limiting age appropriate } \\
\text { instrumental ADL }\end{array}$ & $\begin{array}{l}\text { Severe or medically } \\
\text { significant but not } \\
\text { immediately life- } \\
\text { threatening hospitalization } \\
\text { or prolongation of } \\
\text { existing hospitalization } \\
\text { indicated; disabling; } \\
\text { limiting self care }\end{array}$ & $\begin{array}{l}\text { Life-threatening } \\
\text { consequences; } \\
\text { urgent intervention } \\
\text { indicated }\end{array}$ & Death \\
\hline Hypothyroidism & $\begin{array}{l}\text { Asymptomatic; clinical } \\
\text { or diagnostic } \\
\text { observations only; } \\
\text { intervention not indicated }\end{array}$ & $\begin{array}{l}\text { Symptomatic; thyroid } \\
\text { replacement indicated; } \\
\text { limiting instrumental } \\
\text { ADL }\end{array}$ & $\begin{array}{l}\text { Severe symptoms; } \\
\text { limiting self care; ADL; } \\
\text { hospitalization indicated }\end{array}$ & $\begin{array}{l}\text { Life-threatening } \\
\text { consequences; } \\
\text { urgent intervention } \\
\text { indicated }\end{array}$ & Death \\
\hline Hyperthyroidism & $\begin{array}{l}\text { Asymptomatic; } \\
\text { clinical or diagnostic } \\
\text { observations only; } \\
\text { intervention not indicated }\end{array}$ & $\begin{array}{l}\text { Symptomatic; thyroid } \\
\text { suppression therapy } \\
\text { indicated; limiting } \\
\text { instrumental ADL }\end{array}$ & $\begin{array}{l}\text { Severe symptoms; } \\
\text { limiting self care; ADL; } \\
\text { hospitalization indicated }\end{array}$ & $\begin{array}{l}\text { Life-threatening } \\
\text { consequences; } \\
\text { urgent intervention } \\
\text { indicated }\end{array}$ & Death \\
\hline Adrenalitis & $\begin{array}{l}\text { Asymptomatic; } \\
\text { clinical or diagnostic } \\
\text { observations only; } \\
\text { intervention not indicated }\end{array}$ & $\begin{array}{l}\text { Moderate symptoms; } \\
\text { medical intervention } \\
\text { indicated }\end{array}$ & $\begin{array}{l}\text { Severe symptoms; } \\
\text { hospitalization indicated }\end{array}$ & $\begin{array}{l}\text { Life-threatening } \\
\text { consequences; } \\
\text { urgent intervention } \\
\text { indicated }\end{array}$ & Death \\
\hline
\end{tabular}

The National Cancer Institute has recommended that adverse events on patients with cancer chemotherapy be graded as per the Common Terminology Criteria for Adverse Events (CTCAE) Version 4.03. (U.S. Department of Health and Human Services, National Institutes of Health, National Cancer Institute. Bethesda, MD, USA). Although the published guidelines do not specifically comment on hypophysitis, the toxicity grading structure has been applied to both pituitary function and other endocrine organs.

Table 3. Incidence rates of IRAEs endocrine sequelae. (data from Barroso-Sousa et $\mathrm{al}^{47}$ )

\begin{tabular}{|c|c|c|c|c|c|}
\hline & $\begin{array}{c}\text { Hypophysitis } \\
\text { incidence rate } \\
(95 \% \text { CI })\end{array}$ & $\begin{array}{c}\text { Hypothyroidism } \\
\text { incidence rate } \\
(95 \% \mathrm{CI})\end{array}$ & $\begin{array}{c}\text { Hyperthyroidism } \\
\text { incidence rate } \\
(95 \% \mathrm{CI})\end{array}$ & $\begin{array}{l}\text { Primary adrenal } \\
\text { insufficiency } \\
\text { N of pts with PAI/ } \\
\text { total n of pts }(\%) \%\end{array}$ & $\begin{array}{l}\text { N of pts with DM1/ } \\
\text { total n of pts }(\%)\end{array}$ \\
\hline Anti-CTLA4 & $\begin{array}{l}0.0(0.0-6.7)- \\
6.5(1.4-17.9)\end{array}$ & $\begin{array}{l}0.0(0.0-45.9)- \\
15.2(6.3-28.9)\end{array}$ & $\begin{array}{c}0.0(0.0-45.9)- \\
2.3(0.9-5.0)\end{array}$ & & \multirow{4}{*}{$13 / 5831(0.2 \%)^{* * *}$} \\
\hline Anti-PDL1 & $\begin{array}{l}0.0(0.0-5.9)- \\
3.0(0.1-15.8)\end{array}$ & $\begin{array}{l}0.0(0.0-1.2)- \\
5.6(2.5-10.8)\end{array}$ & $\begin{array}{l}0.0(0.0-1.2)- \\
0.7(0.2-1.8)\end{array}$ & $43 / 5831(0.7 \%)^{* *}$ & \\
\hline Anti-PD1 & & $\begin{array}{c}0.0(0.0-30.8)- \\
40.0(19.1-63.9)\end{array}$ & $\begin{array}{l}0.0(0.0-9.0)- \\
7.7(1.6-20.9)\end{array}$ & & \\
\hline Combination & $\begin{array}{l}3.8(0.5-13.0)- \\
11.7(6.0-20.0)\end{array}$ & $\begin{array}{l}3.8(0.5-13.0)- \\
16.0(9.2-25.0)\end{array}$ & $\begin{array}{c}3.8(0.5-13.0)- \\
9.9(6.8-13.8)\end{array}$ & $11 / 262(4.2 \%)$ & \\
\hline
\end{tabular}

$*_{\text {*number of patients with primary adrenal insufficiency as adverse event following immune check point inhibitors therapy/total number }}$ of patients who received ICIs therapy.

** Refers to pts taking Anti-CTLA4/Anti-PDL1/Anti-PD1; *** Refers to pts taking Anti-CTLA4/Anti-PDL1/Anti-PD1 or combination of them.

PAI: primary adrenal inufficiency; DM1: diabetes mellitus type 1.

activated T cells. Its ligands, PDL1 (B7-H1; CD274) and PDL2 (B7-DC; CD273) are commonly expressed on the surface of antigen-presenting/dendritic cells or macrophages. PD1 and PDL1/PDL2 belong to 
the family of immune checkpoint proteins that act as co-inhibitory factors, which can stop or limit the development of the T cell response. PD1/PDL1 interaction forms a biochemical "shield" protecting tumour cells from being destroyed by the immune system. Monoclonal antibodies that target either PD1 or PDL1 can block this binding and boost the immune response against cancer cells..$^{16,17}$

\section{GENERAL MANAGEMENT OF IMMUNE- RELATED ADVERSE EVENTS}

In general, treatment of moderate or severe IRAEs requires interruption of the checkpoint inhibitor and the use of corticosteroid or alternative immunosuppression. ${ }^{18}$ For grade 2 (moderate) immune-mediated toxicities, treatment with the checkpoint inhibitor should be withheld and not resumed until symptoms or toxicity is grade 1 or less. Corticosteroids (prednisone $0.5 \mathrm{mg} / \mathrm{kg} /$ day or equivalent) should be started if symptoms do not resolve within a week. For patients experiencing grade 3 or 4 (severe or lifethreatening) immune-mediated toxicities, treatment with the checkpoint inhibitor should be permanently discontinued and high doses of corticosteroids (prednisone $1-2 \mathrm{mg} / \mathrm{kg} /$ day or equivalent) should be given. When symptoms subside to grade 1 or less, steroids can be gradually tapered over at least one month. ${ }^{18}$

If symptoms do not clearly improve, particularly after approximately three days with intravenous steroids, infliximab $(5 \mathrm{mg} / \mathrm{kg})$ could be administered rather than continuing with a prolonged course of high-dose IV corticosteroids. ${ }^{18}$ The need for immunosuppressive therapy to manage IRAEs does not appear to affect the response to checkpoint inhibition with either anti-PD1 antibodies or ipilimumab. ${ }^{19}$

The specific approach to each endocrine IRAE is further discussed in the individual sections below.

\section{ENDOCRINE SEQUELAE}

\section{Hypophysitis}

Hypophysitis is a rare inflammatory condition of the pituitary gland with an incidence of 1:1,000,000 in the general population. Byun et al estimated that amongst 2,017 ipilimumab treated patients 184 (9.1\%) developed hypophysitis, while this consequence oc- curred only in $8 / 613(1.3 \%)$ patients on tremelimumab, in $6 / 929(0.4 \%)$ on nivolumab and in $5 / 729(0.68 \%)$ on pembrolizumab therapy. ${ }^{20} \mathrm{~A}$ meta-analysis by AbdelRahman et al estimated a significantly increased risk of all-grade hypophysitis in patients treated with ICIs versus controls (RR: 22.03, 95\% CI: 8.52-56.94). ${ }^{21}$

In contrast, in another meta-analysis of PD1 inhibitors studies the risk of hypophysitis in patients treated with these agents was not significantly elevated compared with controls (RR: 2.32, 95\% CI: 0.574-9.40). ${ }^{22}$ The authors assumed that this discrepancy could be due to the fact that Abdel-Rahman et al analyzed mainly anti-CTLA4 inhibitors studies (five RCTs evaluating ipilimumab, one evaluating tremelimumab, three for nivolumab and one for pembrolizumab), while all ten RCTs included in their analysis were for PD-1 inhibitors. Notably, PD-1 inhibitors induced a significantly lower risk of hypophysitis when directly compared with ipilimumab (RR: 0.148, 95\% CI: 0.043-0.505). This may be explained by the fact that these agents act differently. Anti-CTLA4 therapy can stimulate de novo pituitary-reactive effector $\mathrm{T}$ cells and also lead to the production of anti-pituitary antibodies and activation of the complement, while anti-PD1/PDL1 therapy can make existing pituitary reactive effector $\mathrm{T}$ cells more active. Moreover, the pituitary gland may express CTLA-4, making it a direct target for anti-CTLA-4 antibodies. ${ }^{23}$ Of note, the combination of nivolumab/ipilimumab augmented the risk for hypophysitis versus monotherapy with ipilimumab only (RR: 1.94, 95\% CI 1.07-3.50). ${ }^{22}$

Hypophysitis usually develops between 5-36 weeks of treatment but late occurrence at 19 months has also been reported. ${ }^{20,26}$ Median time to diagnosis of ipilimumab-hypophysitis is nine weeks. ${ }^{24}$ Clinical manifestations relate either to sellar compression as the pituitary enlarges (headache, visual defects) or to hormonal disturbance due to autoimmune inflammation of the pituitary (hypotension, nausea, abdominal pain, anorexia, weight loss, temperature intolerance, loss of libido, polyuria, polydipsia). Many of these symptoms are nonspecific and could be attributed either to pituitary dysfunction or to the underlying illness. Late onset of hypopituitarism without a clinically evident acute phase of inflammation has been reported suggesting a low-grade immunological process against the pituitary. ${ }^{25}$ 
Anterior hypopituitarism is more prevalent than diabetes insipidus, while ACTH and/or TSH deficiency are the most common manifestations. ${ }^{20,26}$ Hypogonadotropic hypogonadism and low levels of insulin-like growth factor 1 (IGF1) may also be present. ${ }^{20}$ Both high and low levels of prolactin have been described. ${ }^{24}$ Older age and male sex may be risk factors for the development of hypophysitis with ICI medications. ${ }^{27}$

It is prudent to perform a baseline hormonal assessment at the initiation of immunotherapy. We suggest that a detailed questionnaire regarding suspicious symptoms for hypophysitis (headache, nausea, weakness, fatigue, hypotension, hypoglycemia) is carried out and measurement of TSH, fT4, morning cortisol (9am), electrolytes, glucose before each cycle is performed, taking into account that both cancer and hypopituitarism may share common symptoms and laboratory results. In the event of compression symptoms (headache, visual defects) and/or clinical suspicion of hypophysitis, then pituitary MRI and a full endocrine work-up (FSH/LH, E2/TESTO, IGF1, PRL, TSH, fT4, cortisol (9am), ACTH) should be performed (Figure 1).

If morning cortisol is less than $250 \mathrm{nmol} / 1$ or random cortisol less than $150 \mathrm{nmol} / 1$ with vague symptoms, then replacement therapy with glucocorticoids should be initiated (Figure 1). In the case of clinical suspicion of adrenal insufficiency or when morning cortisol is $<350 \mathrm{nmol} / 1$, further dynamic ACTH testing is recommended.

Differential diagnosis should exclude the new occurrence of brain metastases, therefore an MRI is mandatory to rule out this possibility and to check pituitary status. Pituitary morphology may change during the disease course, from mild to moderate diffuse enlargement with homogenous or heterogeneous enhancement after contrast administration and stalk thickening at disease onset, to subsequent atrophy of the gland and finally empty sella. Importantly, a normal MRI does not rule out hypophysitis and management should be based on clinical presentation and hormonal evaluation. Occasionally, changes of pituitary morphology may precede function or biochemical disturbances; this may resolve after 1-8 weeks of glucocorticoid therapy. ${ }^{27}$
The management of hypophysitis primarily involves hormone replacement and consideration of ICIs discontinuation and/or high-dose (immunosuppressive) steroid use. Although congruence between treatment plans is lacking, it is suggested that for patients with grade 1 (mild) hypophysitis, immunotherapy may be continued, while for all other grades of toxicities treatment should be withheld and high-dose systemic steroids (prednisolone $0.5-2 \mathrm{mg} / \mathrm{kg} /$ day or equivalent), with subsequent tapering to a physiological replacement dose of hydrocortisone or prednisolone, should be initiated (Figure 1). ${ }^{28}$ Immunotherapy can be restarted once the patient improves clinically and toxicity is grade 1 or less. Appropriate HRT should be added if necessary. Relevant guidelines have recently been published by the European Society of Medical Oncology (ESMO). ${ }^{28}$

While the thyrotroph axis and gonadotroph function may recover, this is not common with corticotroph function. Meanwhile, low prolactin may predict lack of recovery function with a specificity of $88.9 \%$, sensitivity of $50 \%$, negative predictive value of $57.1 \%$, positive predictive value of $85.7 \%$ and accuracy of $66.7 \% .^{29}$

\section{Primary thyroid disorders}

The pattern of primary thyroid disturbances includes subclinical or overt hypothyroidism, painless thyroiditis with transient thyrotoxicosis, subclinical or overt hyperthyroidism and thyroid eye disease. , $^{80-33}$

Abdel-Rahman et al estimated that the risk of all-grade hypothyroidism and hyperthyroidism associated with ICIs therapy is significantly elevated versus controls. Relative risks were 8.26 (95\% CI: 4.67-14.62) and 5.48 (95\% CI: 1.33-22.53), respectively. ${ }^{21}$

In a meta-analysis of PD-1 inhibitors studies the risk of hyperthyroidism was significantly increased compared to anti-CTLA4 (RR 2.45, 95\% CI: 1.19-5.03), while the risk of hypothyroidism, although elevated, did not reach significance (RR: $4.13,95 \%$ CI: 0.85 20.17). ${ }^{22}$ The combination of nivolumab/ipilimumab increased the risk of all-grade hyperthyroidism (RR: 9.13 95\% CI: 3.07-27.11) and hypothyroidism (RR: 2.01 (95\% CI: 0.60-6.70), although again this was not significant for the latter. ${ }^{22}$ 


\begin{tabular}{|c|c|}
\hline \multicolumn{2}{|c|}{$\begin{array}{c}\text { Baseline screening } \\
\text { TSH, fT4, Cortisol (9am), electrolytes, glucose }\end{array}$} \\
\hline \multicolumn{2}{|c|}{$\begin{array}{l}\text { Check for clinical symptoms suggestive of pituitary, thyroid or adrenal disorder and measure } \\
\text { TSH, fT4, cortisol (9am), electrolytes, glucose before each cycle* } \\
\text { * during anti-CTLA-4 treatment: additional TFTs } 4-6 \text { weeks after the last cycle (late thyroid } \\
\text { dusfunction); during anti-PD-1/anti-PD-L1 treatment: TFTs before every cycle for first } 6 \text { cycles, } \\
\text { every second cycle thereafter }\end{array}$} \\
\hline $\begin{array}{l}\text { If compression symptoms (headache, } \\
\text { visual defects) and/or clinical suspicion of } \\
\text { hypophysitis perform pituitary MRI and } \\
\text { endocrine work up (FSH/LH, E2/TESTO, } \\
\text { IGF-1, PRL, TSH, fT4, Cortisol ( } 9 \text { am), ACTH) }\end{array}$ & $\begin{array}{l}\text { If suspicion of primary thyroid disorder } \\
\text { check TSH, fT4, fT3, autoantibodies, anti } \\
\text { TSH-receptor abs, radionuclide scan } \\
\text { If hyperglycemia check ICA, anti-GAD, } \\
\text { C-peptide }\end{array}$ \\
\hline $\begin{array}{l}\text { If morning cortisol }(9 \mathrm{am})<250 \mathrm{nmol} / \mathrm{l} \text { or ran } \\
\text { glucocorticoid replacement }\end{array}$ & rtisol $<150 \mathrm{nmol} / \mathrm{l}$ and vague symptom start \\
\hline
\end{tabular}

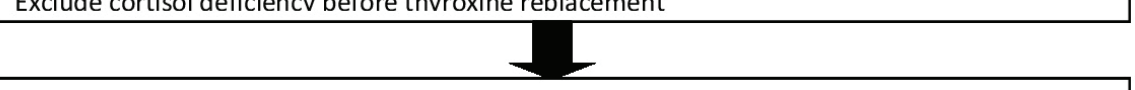

\section{Hypophysitis}

Grade 1: start glucocorticoid replacement (20-10-10 mg/day) with stress day rules, thyroxine replacement if needed $(0.5-1.5 \mu \mathrm{g} / \mathrm{Kg})$, *

Grade 2: (methyl) prednisolone $0.5-1 \mathrm{mg} / \mathrm{kg}$ od, per os and if no improvement in $48 \mathrm{~h}$, treat as Grade 3 or 4 with i.v. (methyl)prednisolone (see below)

Grade 3 or $4 \pm$ edema /visual disorders: give high dose glucocorticoids iv,.((methyl) prednisolone $1-2 \mathrm{mg} / \mathrm{kg} /$ day iv., when symptoms subside to grade 1 or less, corticosteroids can be gradually tapered over at least one month), thyroxine replacement if needed

* continue immunotherapy only in grade 1

\section{Thyroid disorders}

Hypothyroidism (low fT4 with elevation of TSH, or normal fT4 with TSH>10): thyroxine replacement $(0.5-1.5 \mu \mathrm{g} / \mathrm{kg}$, depending on the cardiac history)

Destructive thyroiditis: b-blockers (propranolol or atenolol)

Hyperthyroidism: anti-thyroid drugs, b-blockers, steroids (prednisolone $0.5 \mathrm{mg} / \mathrm{Kg}$ ) **

** in those cases that steroids and anti-thyroid drugs are required, immunotherapy should be discontinued until recovery from symptoms

Primary adrenal insufficiency

Glucocorticoid and mineralocorticoid replacement

Type 1 diabetes mellitus

Insulin

Figure 1. Proposed algorithm for the management of immune related adverse events. FSH: follicle stimulating hormone, LH: luteinizing hormone, E2: estradiol, TESTO: testosterone, IGF-1: insulin growth factor-1, PRL: prolactin, fT4: free T4, TSH: thyroid stimulating hormone. 
In a series of 126 patients treated with ipilimumab for melanoma, one developed primary hypothyroidism, while eight $(6 \%)$ developed subclinical hypothyroidism and $20(16 \%)$ subclinical hyperthyroidism. Of the 46 patients who were treated with anti-PD1 inhibitors for melanoma, six (13\%) developed primary hypothyroidism, a further six (13\%) subclinical hypothyroidism and six $(13 \%)$ developed subclinical hyperthyroidism. Of the 23 patients treated with the combination of ipilimumab and nivolumab for melanoma, four patients $(22.2 \%)$ developed hypothyroidism, one of whom had a preceding episode of hyperthyroidism, and two had preceding subclinical hyperthyroidism. One patient (5.6\%) had subclinical hypothyroidism and a further four patients $(22.2 \%)$ had subclinical hyperthyroidism without subsequent hypothyroidism. Destructive thyroiditis was more common than Graves' disease. ${ }^{31}$ In a study of 93 pembrolizumab treated patients 13 (14\%) developed abnormal thyroid function tests. Thyroiditis occurred in seven patients $(54 \%)$, four of whom recovered. New onset hypothyroidism, either overt or subclinical, developed in three patients. Thyroperoxidase (TPO) antibodies were positive only in 4/13 (31\%) and diffusely increased 18 -FDG uptake of the thyroid gland was observed in $7 / 11(64 \%)$ patients. The authors noticed an increased number of circulating CD56+CD16+ NK cells and an elevated surface expression of HLA-DR in the inflammatory intermediate CD14+CD16+ monocytes and assumed that this may explain the destruction of the thyroid. ${ }^{33}$

The onset of thyroid disease usually occurs after 2-4 cycles of therapy. Aggravation of existing autoimmunity has been reported; ${ }^{33-35}$ however, whether individual genetic susceptibility plays a role has not yet been established. Delivanis et al reported recovery of pembrolizumab-induced thyroiditis in 4/7 $(57 \%)$ patients. ${ }^{33}$ It is noteworthy that two cases with hyperthyroidism who required high-dose systemic corticosteroids for the management of other immunerelated toxicities did not become hypothyroid. ${ }^{31}$ The authors assumed that immunosuppressive therapy may prevent the development of hypothyroidism in those with ICIs-related thyroiditis. This is in contrast to the situation in ipilimumab-induced hypophysitis, where high dose steroids have not been shown to reverse pituitary dysfunction. ${ }^{37}$
TFTs, thyroid autoantibodies and TSH-receptor antibodies and a radionuclide thyroid uptake scan may aid in proper diagnosis.

It is suggested that in patients with symptomatic hyperthyroidism treatment with beta-blockers (propranolol or atenolol/metoprolol) should be started. Symptoms of transient hyperthyroidism due to destructive thyroiditis may be alleviated with beta blockers, as in that case antithyroid drugs are not indicated. ${ }^{28} \mathrm{In}$ the case of painful thyroiditis prednisolone $0.5 \mathrm{mg} / \mathrm{kg}$ may be started with subsequent tapering. In the event of positive anti-TSH receptor antibodies carbimazole may be initiated. Treatment with ICIs should be interrupted until recovery from symptoms. ${ }^{28}$

In the case of hypothyroidism, thyroxine replacement $0.5-1.5 \mu \mathrm{g} / \mathrm{Kg}$ should be initiated. In subclinical hypothyroidism, substitution with thyroid hormone should be considered in the case of fatigue or other complaints that could be attributed to hypothyroidism. ICIs may be continued. ${ }^{28}$

A decrease in TSH levels across two measurements with normal or lowered fT4 may indicate the development of hypophysitis and thus weekly cortisol measurements should also be performed. ${ }^{28}$

\section{Adrenalitis}

Case reports of primary adrenal dysfunction with the use of immune checkpoint inhibitors have been published, while patients receiving these drugs require education on the potential risks of hypocortisolemia, which may be fatal if left untreated.

In the review by Byun et al, two cases of primary adrenal insufficiency are reported amongst 256 patients $(0.8 \%)$ treated with ipilimumab..$^{20,38,39}$ Trainer et al described a patient with hyponatremia secondary to nivolumab-induced primary adrenal failure. The patient's FDG PET CT scan demonstrated bilateral increased FDG activity in the adrenals consistent with autoimmune adrenalitis. ${ }^{40}$ Adrenal insufficiency of unspecified cause has been reported in patients treated with tremelimumab, nivolumab and the combination of anti-CTLA4 and anti-PD1 agents. ${ }^{42}$ Unfortunately, most of the reports do not specify the etiology of adrenal insufficiency. Overall, the relative risk of adrenal insufficiency of any cause was significantly 
elevated (RR: 3.87 (95\% CI: 1.12-13.41) as described in a review by Abdelrahman et al. ${ }^{21}$

Although hyponatremia can occur in patients with ACTH deficiency, the possibility of primary adrenal failure should also be considered and investigated by measurement of renin, aldosterone and ACTH. There have been reports of radiological evidence of adrenalitis with normal endocrine function, following ICIs therapy, consistent with a subclinical form of adrenalitis. ${ }^{39}$ When adrenal enlargement is observed in patients receiving immune checkpoint drugs, assessment of adrenal function through the measurement of ACTH and cortisol levels, as well as a Synacthen stimulation test, should be performed so as to rule out primary adrenal insufficiency.

\section{Type 1 diabetes mellitus}

Type 1 diabetes mellitus (T1DM) is a rare complication of anti-PD1 or anti-PDL1 agents. Antibodies against islet cell antigens have been detected in a few of the reported cases. ${ }^{43,44}$ Time to development ranges from less than 1 month to 1 year. Insulin therapy is the mainstay of treatment. The use of glucocorticoids was not able to reverse T1DM in a patient treated with pembrolizumab for metastatic melanoma. ${ }^{45}$

The proposed mechanism for the development of T1DM is that lower PD-1 expressing CD4+ cells may lead to activation of autoreactive $T$ cells that can infiltrate pancreatic islet cells and ultimately lead to T1DM. ${ }^{41}$ It is suspected that high-risk HLA class I and II genotypes may be associated. It is recommended that clinicians managing patients undergoing anti-PD1 or anti-PDL1 therapy should carefully monitor patients for elevated levels of blood sugar, while antibodies against islet cell (ICA) and glutamic acid decarboxylase (GAD) and C-peptide should be measured in order to distinguish between T1DM and T2DM (Figure 1).

\section{CONCLUDING REMARKS}

ICIs targeting CTLA-4 and PD-1/PDL-1 have dramatically changed the outcome of patients with several advanced-stage malignancies. However, their use is associated with unique IRAEs (hypophysitis, thyroid disorders, adrenalitis, type 1 diabetes mel- litus) which, though mostly transient and mild, can occasionally be fatal. At the time this manuscript was being prepared a case of primary hypoparathyroidism caused by ipilimumab and nivolumab and manifesting with acute severe symptomatic hypocalcemia was reported as a new IRAE. ${ }^{46}$ Rapid identification of these IRAEs and appropriate treatment can improve the outcome of immunotherapy.

It is important that patients on ICIs are informed about the potential endocrine sequelae of these treatments and especially the risk of developing cortisol deficiency due to either pituitary or adrenal failure. Close monitoring and constant vigilance for the occurrence of IRAEs are necessary. As T-cell checkpoint inhibitors are now achieving regulatory approval in many types of cancer, more data on conducting the long-term follow-up of these patients is urgently required.

\section{LEARNING POINTS}

The relative risk of hypophysitis is high in those treated with anti-CTLA4 agents.

When compared with ipilimumab, the risk of allgrade hyperthyroidism and hypothyroidism with PD-1 inhibitors monotherapy seems to be higher, while the risk of all-grade hypophysitis is lower.

Patients treated with a nivolumab/ipilimumab combination therapy have a significantly increased risk of all-grade hyperthyroidism and hypophysitis when compared with ipilimumab monotherapy.

Adrenalitis and type 1 diabetes mellitus are rare IRAEs of immune checkpoint inhibitors.

Long-term follow-up of patients treated with T-cell checkpoint inhibitors is needed so that more data may be gathered on the immune-related endocrinopathies.

\section{DECLARATION OF INTEREST}

The authors declare that they have no conflict of interest.

\section{FUNDING}

This study was not funded. 


\section{REFERENCES}

1. Hodi FS, O’Day SJ, McDermott DF, et al, 2010 Improved survival with ipilimumab in patients with metastatic melanoma. N Engl J Med 363: 711-723.

2. Larkin J, Chiarion-Sileni V, Gonzalez R, et al, 2015 Combined nivolumab and ipilimumab or monotherapy in untreated melanoma. N Engl J Med 373: 23-34.

3. Antonia SJ, López-Martin JA, Bendell J, et al, 2016 Nivolumab alone and nivolumab plus ipilimumab in recurrent small-cell lung cancer (CheckMate 032): a multicentre, open-label, phase 1/2 trial. Lancet Oncol 17: 883-895.

4. Davids MS, Kim HT, Bachireddy P, et al, 2016 Leukemia and Lymphoma Society Blood Cancer Research Partnership. Ipilimumab for patients with relapse after allogeneic transplantation. N Engl J Med 375: 143-153.

5. George S, Motzer RJ, Hammers HJ, et al, 2016 Safety and efficacy of nivolumab in patients with metastatic renal cell carcinoma treated beyond progression: A subgroup analysis of a randomized clinical trial. JAMA Oncol 2: 1179-1186.

6. Faje AT, Sullivan R, Lawrence D, et al, 2014 Ipilimumabinduced hypophysitis: a detailed longitudinal analysis in a large cohort of patients with metastatic melanoma. J Clin Endocrinol Metab 99: 4078-4085.

7. McMillen B, Dhillon MS, Yong-Yow S, 2016 A rare case of thyroid storm. BMJ Case Rep, doi: 10.1136/ bcr-2016-214603.

8. Min L, Vaidya A, Becker C, 2011 Thyroid autoimmunity and ophthalmopathy related to melanoma biological therapy. Eur J Endocrinol 164: 303-307.

9. Yamauchi I, Sakane Y, Fukuda Y, et al, 2017 Clinical features of nivolumab-induced thyroiditis: A case series study. Thyroid 27: 894-901.

10. Khan U, Rizvi H, Sano D, Chiu J, Hadid T, 2017 Nivolumab induced myxedema crisis. J Immunother Cancer 5: 13.

11. Godwin JL, Jaggi S, Sirisena I, et al, 2017 Nivolumabinduced autoimmune diabetes mellitus presenting as diabetic ketoacidosis in a patient with metastatic lung cancer. J Immunother Cancer 5: 40.

12. Chen DS, Mellman I, 2013 Oncology meets immunology: the cancer-immunity cycle. Immunity 39: 1-10.

13. Fathman CG, Lineberry NB, 2007 Molecular mechanisms of CD4+ T-cell anergy. Nat Rev Immunol 7: 599-609.

14. Zou W, 2006 Regulatory cells, tumour immunity and immunotherapy. Nat Rev Immunol 6: 295-307.

15. Kavanagh B, O'Brien S, Lee D, et al, 2008 CTLA4 blockade expands FoxP3+ regulatory and activated effector CD4+ T cells in a dose-dependent fashion. Blood 112: 1175-1183.

16. Okazaki T, Honjo T, 2007 PD-1 and PD-1 ligands: from discovery to clinical application. Int Immunol 19: 813-824.

17. Brown JA, Dorfman DM, Ma FR, et al, 2003 Block- ade of programmed death-1 ligands on dendritic cells enhances $\mathrm{T}$ cell activation and cytokine production. J Immunol 170: 1257-1266.

18. https:/www.uptodate.com/contents/toxicities-associatedwith checkpoint-inhibitor-immunotherapy.

19. Horvat TZ, Adel NG, Dang TO, et al, 2015 Immunerelated adverse events, need for systemic immunosuppression, and effects on survival and time to treatment failure in patients with melanoma treated with ipilimumab at Memorial Sloan Kettering Cancer Center. J Clin Oncol 33: 3193-3198.

20. Byun DJ, Wolchok JD, Rosenberg LM, Girotra M, 2017 Cancer immunotherapy-immune checkpoint blockade and associated endocrinopathies. Nat Rev Endocrinol 13: 195-207.

21. Abdel-Rahman O, El Halawani H, Fouad M, 2016 Risk of endocrine complications in cancer patients treated with immune check point inhibitors: a meta-analysis. Future Oncol 12: 413-425.

22. Shang YH, Zhang Y, Li JH, Li P, Zhang X, 2017 Risk of endocrine adverse events in cancer patients treated with PD-1 inhibitors: a systematic review and metaanalysis. Immunotherapy 9: 261-272.

23. Iwama S, De Remigis A, Callahan MK, Slovin SF, Wolchok JD, Caturegli P, 2014 Pituitary expression of CTLA-4 mediates hypophysitis secondary to administration of CTLA-4 blocking antibody. Sci Transl Med 6: $230 \mathrm{ra} 45$.

24. Cukier P, Santini FC, Scaranti M, Hoff AO, 2017 Endocrine side effects of cancer immunotherapy. Endocr Relat Cancer 12: T331-T347.

25. Vancieri G, Bellia A, Lauro D, 2016 Late-onset panhypopituitarism in a 72-year-old male patient treated with ipilimumab for metastatic melanoma: a case report. J Endocrinol Invest 39: 805-806.

26. Ryder M, Callahan M, Postow MA, Wolchok J, Fagin JA, 2014 Endocrine-related adverse events following ipilimumab in patients with advanced melanoma: a comprehensive retrospective review from a single institution. Endocr Relat Cancer 21: 371-381.

27. Faje A, 2016 Immunotherapy and hypophysitis: clinical presentation, treatment, and biologic insights. Pituitary 19: 82-92.

28. Haanen JBAG, Carbonnel F, Robert C, et al, 2017 Management of toxicities from immunotherapy: ESMO Clinical Practice Guidelines for diagnosis, treatment and follow-up. Annals of Oncology 28: iv119-iv142.

29. Araujo PB, Coelho MC, Arruda M, Gadelha MR, Neto LV, 2015 Ipilimumab-induced hypophysitis: review of the literature. J Endocrinol Invest 38: 1159-1166.

30. Rossi E, Sgambato A, De Chiara G, et al, 2016 Endocrinopathies induced by immune-checkpoint inhibitors in advanced non-small cell lung cancer. Expert Rev Clin Pharmacol 9: 419-428.

31. Morganstein DL, Lai Z, Spain L, et al, 2017 Thyroid abnormalities following the use of cytotoxic T-lymphocyte 
antigen-4 and programmed death receptor protein-1 inhibitors in the treatment of melanoma. Clin Endocrinol (Oxf) 86: 614-620.

32. de Filette J, Jansen Y, Schreuer M, et al, 2016 Incidence of thyroid-related adverse events in melanoma patients treated with pembrolizumab. J Clin Endocrinol Metab 101: 4431-4439.

33. Delivanis DA, Gustafson MP, Bornschlegl S, et al, 2017 Pembrolizumab-induced thyroiditis. Comprehensive clinical review and insights into underlying involved mechanisms. J Clin Endocrinol Metab 102: 2770-2780.

34. Guaraldi F, La Selva R, Samà MT, et al, 2017 Characterization and implications of thyroid dysfunction induced by immune checkpoint inhibitors in real-life clinical practice: a long-term prospective study from a referral institution. J Endocrinol Invest, doi: 10.1007/ s40618-017-0772-1.

35. Gutzmer R, Koop A, Meier F, et al, 2017 Programmed cell death protein-1 (PD-1) inhibitor therapy in patients with advanced melanoma and preexisting autoimmunity or ipilimumab-triggered autoimmunity. Eur J Cancer 75: 24-32.

36. Narita, T, Oiso, N, Taketomo, Y, et al, 2016 Serological aggravation of autoimmune thyroid disease in two cases receiving nivolumab. The Journal of Dermatology 43: 210-214.

37. Min L, Hodi FS, Giobbie-Hurder A, et al, 2015 Systemic high-dose corticosteroid treatment does not improve the outcome of ipilimumab-related hypophysitis: a retrospective cohort study. Clin Cancer Res 21: 749-755.

38. Min L, Ibrahim N, 2013 Ipilimumab-induced autoimmune adrenalitis. Lancet Diabetes Endocrinol 1: e15.

39. Bacanovic S, Burger IA, Stolzmann P, Hafner J, Huellner MW, 2015 Ipilimumab-induced adrenalitis: A possible pitfall in 18F-FDG-PET/CT. Clin Nucl Med 40: e518519.

40. Trainer H, Hulse P, Higham CE, Trainer P, Lorigan $P$, 2016 Hyponatraemia secondary to nivolumab-induced primary adrenal failure. Endocrinol Diabetes Metab Case Rep, 16-0108.

41. Zamani MR, Aslani S, Salmaninejad A, Javan MR, Rezaei N, 2016 PD-1/PD-L and autoimmunity: A growing relationship. Cell Immunol 310: 27-41.

42. Hellmann MD, Rizvi NA, Goldman JW, et al, 2017 Nivolumab plus ipilimumab as first-line treatment for advanced non-small-cell lung cancer (CheckMate 012): results of an open-label, phase 1, multicohort study. Lancet Oncol 18: 31-41.

43. Li L, Masood A, Bari S, Yavuz S, Grosbach AB, 2017 Autoimmune diabetes and thyroiditis complicating treatment with nivolumab. Case Rep Oncol 10: 230-234.

44. Godwin JL, Jaggi S, Sirisena I, et al, 2017 Nivolumabinduced autoimmune diabetes mellitus presenting as diabetic ketoacidosis in a patient with metastatic lung cancer. J Immunother Cancer 5: 40.

45. Aleksova J, Lau PK, Soldatos G, McArthur G, 2016 Glucocorticoids did not reverse type 1 diabetes mellitus secondary to pembrolizumab in a patient with metastatic melanoma. BMJ Case Rep, bcr2016217454.

46. Win MA, Thein KZ, Qdaisat A, Yeung SJ, 2017 Acute symptomatic hypocalcemia from immune checkpoint therapy-induced hypoparathyroidism. Am J Emerg Med 35: 1039.e5-1039.e7.

47. Barroso-Sousa R, Barry WT, Garrido-Castro AC, et al, 2017 Incidence of endocrine dysfunction following the use of different immune checkpoint inhibitor regimens: A systematic review and meta-analysis. JAMA Oncol, doi: 10.1001/jamaoncol.2017.3064. 